\title{
Practice implications of an antimicrobial stewardship intervention in a tertiary care teaching hospital, Qatar
}

Ziad Nasr, ${ }^{1}$ Alya Babiker, ${ }^{1}$ Marwa Elbasheer, ${ }^{1}$ Aisha Osman, ${ }^{1}$ Shereen Elazzazy ${ }^{2}$ and Kyle John Wilby ${ }^{1}$

${ }^{1}$ Clinical Pharmacy and Practice, College of Pharmacy, Qatar University, Doha, Qatar. ${ }^{2}$ National Center for Cancer Care and Research (NCCCR), Doha, Qatar. (Correspondence to: Ziad G. Nasr: znasr@qu.edu.qa).

\begin{abstract}
Background: Antibiotic misuse is a worldwide public health problem and has been associated with increased morbidity, length of hospital stay, mortality, healthcare costs, and most importantly antibiotic resistance.

Aims: We aimed to evaluate the compliance of antibiotic prescribing with national guidelines, assess how educational interventions can best be utilized to make impact and fill gaps for optimal antibiotic utilization, and to identify facilitators and barriers to implementing ASPs in Qatar.

Methods: Six cross-sectional baseline audits of antibiotic prescribing were conducted over a two-week period at a tertiary care teaching hospital. A sub-analysis of prescriptions with follow up has followed. An educational intervention utilizing the PDSA (Plan-Do-Study-Act) tool was implemented to address gaps identified. A repeated audit was done to assess the impact of change. Lastly, interviews were conducted to recognize perceived facilitators and barriers for ASP implementation, identify strategies to overcome barriers, and evaluate the effectiveness of educational interventions.

Results: The most common indication for antibiotic prescribing was febrile neutropenia (20.7\%). The most frequently used class of antibiotics was carbapenems (21.4\%). Sixty percent of prescriptions complied with guidelines. The rationale behind choosing not to adhere to guidelines was not documented in $37.2 \%$ of cases. Suboptimal documentation in records was targeted through our intervention. The audit post intervention showed slight improvement in documentation. Facilitators and barriers included: collaboration and communication among teams, compliance with guidelines, interventions documented by clinical pharmacists, and electronic system errors.
\end{abstract}

Conclusions: Effective communication, continuous documentation in records, and repetitive education promote rational antibiotic prescribing and enhance ASPs.

Keywords: antibiotics, antimicrobial stewardship, educational intervention, clinical practice, Qatar

Citation: Nasr ZG; Babiker A; Elbasheer M; Osman A; Elazzazy S; Wilby KJ. Practice implications of an antimicrobial stewardship intervention in a tertiary care teaching hospital, Qatar. East Mediterr Health J. 2019;25(3):172-180 https://doi.org/10.26719/emhj.18.026

Received: 04/09/17; accepted: 08/03/18

Copyright (c) World Health Organization (WHO) 2019. Some rights reserved. This work is available under the CC BY-NC-SA 3.0 IGO license (https:// creativecommons.org/licenses/by-nc-sa/3.0/igo).

\section{Introduction}

Antibiotics are among the most commonly prescribed medications in hospital settings yet inappropriate utilization frequently occurs (1). Antibiotic misuse is associated with increased mortality, morbidity, length of hospital stay, cost of healthcare, and most importantly antibiotic resistance (1). Antimicrobial Stewardship refers to a set of coordinated interventions intended to optimize the use of antimicrobials in various settings including outpatient clinics and inpatient healthcare settings $(2,3)$. In fact, the proper use of antibiotics leads to enhancing drug and patient safety, reducing drug consumption and cost containment, limiting the emergence of resistant organisms, with an end goal of improving patient outcomes (4). Antimicrobial stewardship programmes (ASPs) are designed to ensure appropriate selection of an effective antimicrobial drug regimen, dose, time, duration of therapy, and route of administration (5). An effective programme is one that is led by a coalition of physicians, clinical pharmacists and other healthcare members, and is committed to leadership where necessary humanistic, financial, information technology, and time resources are implemented (6-9).

Several antimicrobial stewardship strategies have been previously evaluated in hospital settings such as streamlining, prospective audit with feedback, formulary restriction and preauthorization, amongst others $(4,5)$. Such interventions can be only successful if they meet the specific needs of the healthcare institution with dedicated work between healthcare professionals, administrators, information technology personnel, and policy-makers $(2,10)$. Point prevalence studies (PPSs) serve as audit markers and practical surveillance tools to monitor antibiotic prescribing patterns over time (11). They tend to assess antibiotic use across and within healthcare settings, identify targets for quality enhancement, and track differences in practices between institutions (12). Moreover, monitoring antibiotic use and prescribing and identifying resistance patterns is crucial in identifying opportunities for improvement, and strategies to overcome barriers associated with antibiotic misuse (13). In addition, regular reporting of information on antibiotic use and outcome results to multidisciplinary teams serves as a key element of successful ASPs (13). In fact, 
education and ongoing training opportunities should be readily available for healthcare professionals with an aim to promote effective antibiotic prescribing (14).

Patients diagnosed with cancer, in particular with hematologic malignancies and neutropenia, tend to be more vulnerable to acquiring infections such as Clostridium difficile infection (CDI), bloodstream and other organ infections caused by multi-drug resistant organisms (MDROs) (15,16). Thus, antibiotics are often prescribed for both treatment and prophylaxis. In fact, appropriate antibiotic selection, rationale behind the use of antibiotics, and proper adherence to a successful ASP in such population was associated with lower mortality rates (17). A previous PPS conducted by Hammuda et al. in Qatar at the National Center for Cancer Care and Research (NCCCR) showed that only $57.6 \%$ of antibiotic prescriptions met national treatment guidelines or followed local antibiotic prescribing policies (18). Since the time of that study conduction, local guidelines have been updated and the institution has introduced an ASP led by a physician and a dedicated clinical pharmacist. However, no systematic evaluation of this service has occurred to date as well as any impact of educational interventions on clinical practice.

This study targets four objectives; primarily, we aimed to evaluate antibiotic prescribing in cancer patients by assessing compliance with local prescribing guidelines over multiple time points by performing baseline PPSs. This was followed by a prospective audit to characterize and assess antibiotic interventions during the patient's follow-up period by tracking the prescribing and resistance patterns based on culture results. Secondly, we aimed to educate the multidisciplinary team of our findings and provide feedback using the "Plan, Do, Study, Act" (PDSA) quality improvement tool adopted from the Institute of Healthcare Improvement. Thirdly, we intended to evaluate the impact of the educational intervention on AMS by repeating a second antibiotic audit. Lastly, we aimed to identify facilitators and barriers to ASP implementation in Qatar through interviews with pharmacists who witnessed the educational intervention.

\section{Data sources and methods}

\section{Phase 1: Baseline PPSs with prospective follow up on antibiotic therapy}

Six cross-sectional audits of antibiotic prescribing were conducted at NCCCR in Qatar. NCCCR is a 65-bed tertiary care teaching hospital that admits oncology/haematology, palliative care, and bone marrow transplant patients. The PPSs were performed on six separate days over an 11-day period between February 14 and February 24, 2016. Six PPSs were conducted to account for variations in weekly prescribing, as well as prescriber dependent prescribing; as consulting physicians typically rotate on a weekly basis. The audits were conducted on a Sunday, Monday, and Wednesday of each of the two weeks. All data was collected from electronic healthcare records at NCCCR. This hospital documents all patient information using CERNER ${ }^{\oplus}$ (Missouri MO, United States of America). Ethical approval was obtained from the Qatar University Institutional Review Board (QU-IRB 521-E/15), and Hamad Medical Corporation, Medical Research Center (15415/15).

All patients admitted on each study day were assessed for inclusion. Patients were included if they received at least one systemic antibacterial agent on the study day. Patients receiving antibiotics through outpatient intravenous programs were excluded. Patient receiving anti-tuberculosis, anti-fungal or anti-viral prescriptions were also excluded. On each day, all medical wards were audited using an adapted modified audit tool: 2006 European Surveillance of Antibiotic Consumption Point Prevalence Survey (ESAC PPS) Audit Tool (19). Data was collected by three pharmacy students, a research collaborator, and the primary research investigator. A senior investigator verified all data. Data collected included: age, gender, antimicrobial agent (dose, route, frequency and duration); classified according to the World Health Organization's anatomical therapeutic chemical (ATC) classification system (20), treatment indication, guideline compliance, and documentation of rationale if guidelines were not adhered to. Guideline compliance was determined using institutional antibiotic prescribing policies, which refer to preauthorized antibiotics policies, and are based on local antibiogram data; however, they are primarily in line with guidelines from the Infectious Diseases Society of America (IDSA) or other tertiary references $(21,22)$.

The second part of phase 1 included a prospective observation and assessment of physicians' prescribing behaviour during patient follow-up period, that applies to patients with length of hospital stay of at least 48 hours and have received two doses or more of an antibiotic on those days. Culture and sensitivity results were taken into account for these patients (bug/drug mismatch, escalation or streamlining of therapy). This was performed over 14 days as per our study protocol. Data was entered into the IBM ${ }^{\oplus}$ SPSS $^{\circledR}$ Statistics V23.0 (New York NY, United States of America) software for analysis. Data was analyzed descriptively.

\section{Phase 2: Feedback using an educational intervention}

An educational intervention was performed to evaluate the results obtained from the first phase of our study; specifically, to address the gaps and areas for improvement that were identified. The "Plan-Do-Study-Act" (PDSA) model was utilized which is a quality improvement tool implemented by the Institution for Health Improvement with the goal of establishing a functional association between process changes in healthcare systems and variations in outcomes $(23,24)$. We performed an on-spot bed-side educational intervention during multidisciplinary rounds on the wards targeting all stakeholders (each team consisted of a consultant, medical fellow, medical resident, clinical pharmacist and a nurse) within four medical teams (infectious diseases, oncology, he- 
matology/bone marrow transplantation, and palliative care) to inform them about the goal of the intervention and to gather feedback for future improvement. After implementation, the intervention was studied in terms of impact on practice. This methodology is adapted from a well-established PDSA model used for interventional techniques aiming to promote changing behaviors (23).

\section{Phase 3: Impact of change}

After the interventional period was complete, an audit of prescribing behaviours was repeated to assess the impact of change. The medical records were reviewed post the intervention on the same day of the intervention. The main outcome measure we looked at was to address the improvement of documentation in patients' electronic healthcare records and to determine whether the intervention did address the gaps identified on the same day of the educational intervention after the multidisciplinary rounds were over. The same statistical analysis approach in phase 1 of the study was used to interpret the results obtained. A PDSA worksheet adapted from the Institute for Healthcare Improvement was used to document a test of change (23).

\section{Phase 4: Qualitative thematic analysis}

In order to identify facilitators and barriers to effective implementation of ASPs within Qatar, a qualitative research study was conducted that aimed to identify perceptions of pharmacists regarding stewardship principles, procedures, and sustainability, in addition to evaluate the effectiveness of educational interventions on the enhancement of AMS in the future. A pre-defined topic guide for the semi-structured interviews was developed. The guide included 10 open-ended questions. The interviewing process took place at NCCCR. Every interview began with an engagement question followed by a series of exploratory questions and ended with an exit question. All interviews were recorded using a recording device and an informed consent was obtained prior to initiating the process. Each interview lasted between 20 and 30 minutes. Each interview was transcribed verbatim which was reviewed by the primary research investigator for accuracy and completeness. Transcripts then underwent a content analysis using an inductive, open-coding approach (25).

\section{Results}

\section{Phase 1: Prospective audit}

\section{Six-point prevalence studies}

The mean age of patients whose medical records were audited was 47.2 years with a predominance of the male gender (70.5\%). Table 1 shows the different types of infections for which an antibiotic was prescribed. The most common documented reason for prescribing antibiotics was febrile neutropenia (20.7\%) followed by bacteremia (14.7\%). However, rationale for antibiotic use was

\section{Figure 1 Usage of antibiotics by classes}
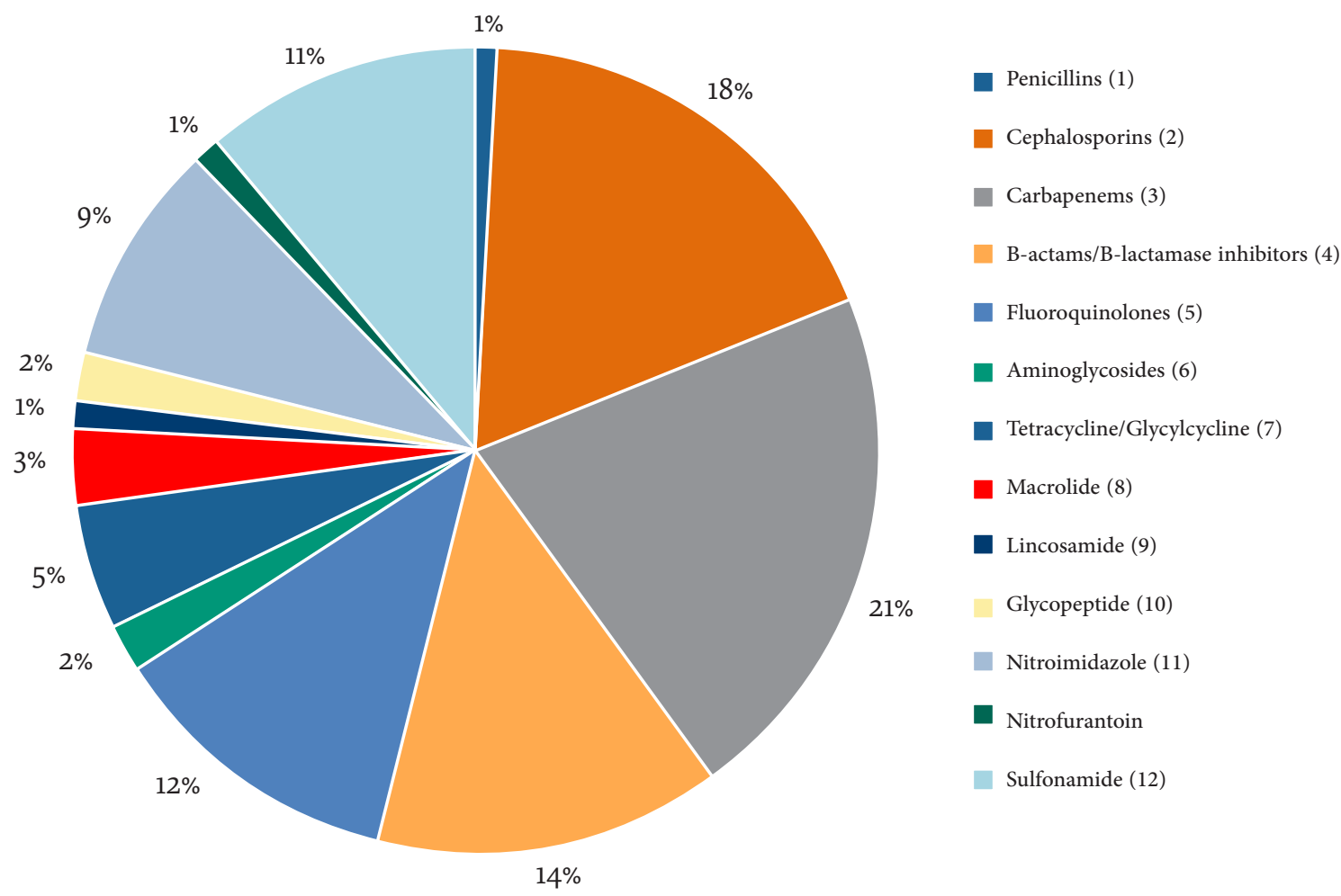

1: amoxicillin, ampicillin, penicillin; 2: cefazolin, cefuroxime, ceftriaxone, cefepime; 3: ertapenem, meropenem; 4: amoxicillin/ clavulanic acid, piperacillin/tazobactam; 5: ciprofloxacin, levofloxacin, lomefloxacin, moxifloxacin; 6: amikacin, gentamicin; 7: doxycycline/tigecycline; 8: azithromycin; 9: clindamycin; 10: vancomycin; 11: metronidazole; 12: trimethoprim/sulfamethoxazole 


\begin{tabular}{lcccccc}
\hline Table 1 Usage of antibiotics by indication & & & & & & \\
Indication* N (\%) & PPS1 & PPS2 & PPS3 & PPS4 & PPS5 & PPS6 \\
HEENT infection & $2(5.1 \%)$ & $2(5.4 \%)$ & $2(5.9 \%)$ & $2(5.3 \%)$ & $2(5.3 \%)$ & $0(0.0 \%)$ \\
SSS infection & $1(2.6 \%)$ & $2(5.4 \%)$ & $4(12.0 \%)$ & $6(16.0 \%)$ & $6(16.0 \%)$ & $5(15.0 \%)$ \\
CAP & $1(2.6 \%)$ & $3(8.1 \%)$ & $1(2.9 \%)$ & $2(5.3 \%)$ & $2(5.3 \%)$ & $0(0.0 \%)$ \\
HAP & $2(5.1 \%)$ & $2(5.4 \%)$ & $1(2.9 \%)$ & $1(2.6 \%)$ & $1(2.6 \%)$ & $2(6.1 \%)$ \\
PJP prophylaxis & $3(7.7 \%)$ & $3(8.1 \%)$ & $4(12.0 \%)$ & $3(7.9 \%)$ & $3(7.9 \%)$ & $3(9.1 \%)$ \\
GI infection & $6(15.0 \%)$ & $5(14.0 \%)$ & $6(18.0 \%)$ & $6(16.0 \%)$ & $3(7.9 \%)$ & $3(9.1 \%)$ \\
UT infection (complicated/uncomplicated cystitis/ & $2(5.1 \%)$ & $2(5.4 \%)$ & $1(2.9 \%)$ & $1(2.6 \%)$ & $1(2.6 \%)$ & $2(6.1 \%)$ \\
catheter-acquired) & & & & & & \\
Blood infection (bacteremia) & $8(21.0 \%)$ & $6(16.0 \%)$ & $5(15.0 \%)$ & $5(13.0 \%)$ & $4(11.0 \%)$ & $4(12.0 \%)$ \\
Febrile neutropenia & $8(21.0 \%)$ & $7(19.0 \%)$ & $8(24.0 \%)$ & $8(21.0 \%)$ & $7(18.0 \%)$ & $7(21.0 \%)$ \\
Undefined/unknown & $6(15.0 \%)$ & $5(14.0 \%)$ & $2(5.9 \%)$ & $4(11.0 \%)$ & $9(24.0 \%)$ & $7(21.0 \%)$ \\
Total & 39 & 37 & 34 & 38 & 38 & 33 \\
\hline
\end{tabular}

*HEENT: head-eye-ear-nose-throat; SSS: skin and skin structure; CAP: community-acquired pneumonia; HAP: hospital-acquired pneumonia; PJP: Pneumocystis Jirovecii Pneumonia; GI: gastrointestinal; UT: urinary tract

not present in $15.2 \%$ of cases. The most frequently used class of antibacterial agents was carbapenems (21.4\%), then cephalosporins (18.2\%), followed by beta-lactam/beta-lactamase inhibitor combinations (14.1\%). Frequencies of prescribed antibacterial agents per day throughout the total 6 days are outlined in Figure 1. The majority of antibiotics were given via the intravenous route $(58.4 \%)$. The majority of prescriptions complied with local prescribing guidelines (59.5\%). The rationale behind choosing not to adhere to clinical practice guidelines was not documented in $37.2 \%$ of the cases.

\section{Prospective follow-up}

Follow-up data were collected as a secondary objective to determine the appropriateness of antibiotic utilization during the hospital stay in patients who stayed at least two days in the hospital and received at least two antibiotic doses on those days. Pre/post-culture and susceptibility results was taken into account. A total of 46 prescriptions were tracked over the two-week period. 95.7\% (44/46) of cases were deemed to have an appropriate follow-up measure. In fact, antibiotics were appropriately streamlined or discontinued after culture results came out or after the patients' clinical improvement. Also, antibiotics were reasonably escalated for broader-spectrum empiric antibacterial coverage or upon clinical deterioration. Only two inappropriate measures were reported where an antibiotic was continued or switched to another antibiotic with no clear indication or rationale. Table 2 summarizes the appropriateness of the measures assessed during the follow-up period.

Table 2 Prospective sub-analysis with follow up based on pre/post culture and susceptibility results

\begin{tabular}{|c|c|c|c|}
\hline \multirow[t]{2}{*}{ Measure } & \multirow[t]{2}{*}{$\mathbf{N}=$ cases } & \multicolumn{2}{|c|}{ Appropriateness } \\
\hline & & Yes & No \\
\hline $\begin{array}{l}\text { Culture results positive targeting specific organism (whether } \\
\text { sensitivity results are available or not) }\end{array}$ & 14 & 14 & 0 \\
\hline $\begin{array}{l}\text { Culture results pending or negative; antibiotic escalated/de- } \\
\text { escalated after clinical improvement/deterioration or hemodynamic } \\
\text { instability }\end{array}$ & 8 & 8 & 0 \\
\hline $\begin{array}{l}\text { Culture results negative or clinical improvement; antibiotic } \\
\text { discontinued }\end{array}$ & 5 & 5 & 0 \\
\hline Antibiotic switch from IV to PO & 1 & 1 & 0 \\
\hline $\begin{array}{l}\text { Patient discharged; antibiotic to be continued at home as per } \\
\text { documentation in medical chart }\end{array}$ & 2 & 2 & 0 \\
\hline $\begin{array}{l}\text { Antibiotic course completed based on previous sensitivity results or } \\
\text { clear indication; patient discharged }\end{array}$ & 10 & 10 & 0 \\
\hline Antibiotic continued with no alteration in regimen & 4 & 4 & 0 \\
\hline $\begin{array}{l}\text { Antibiotic continued or antimicrobial switching with no clear } \\
\text { indication or rationale }\end{array}$ & 2 & 0 & 2 \\
\hline Total & $N=46$ & $95.7 \%$ & $4.3 \%$ \\
\hline
\end{tabular}




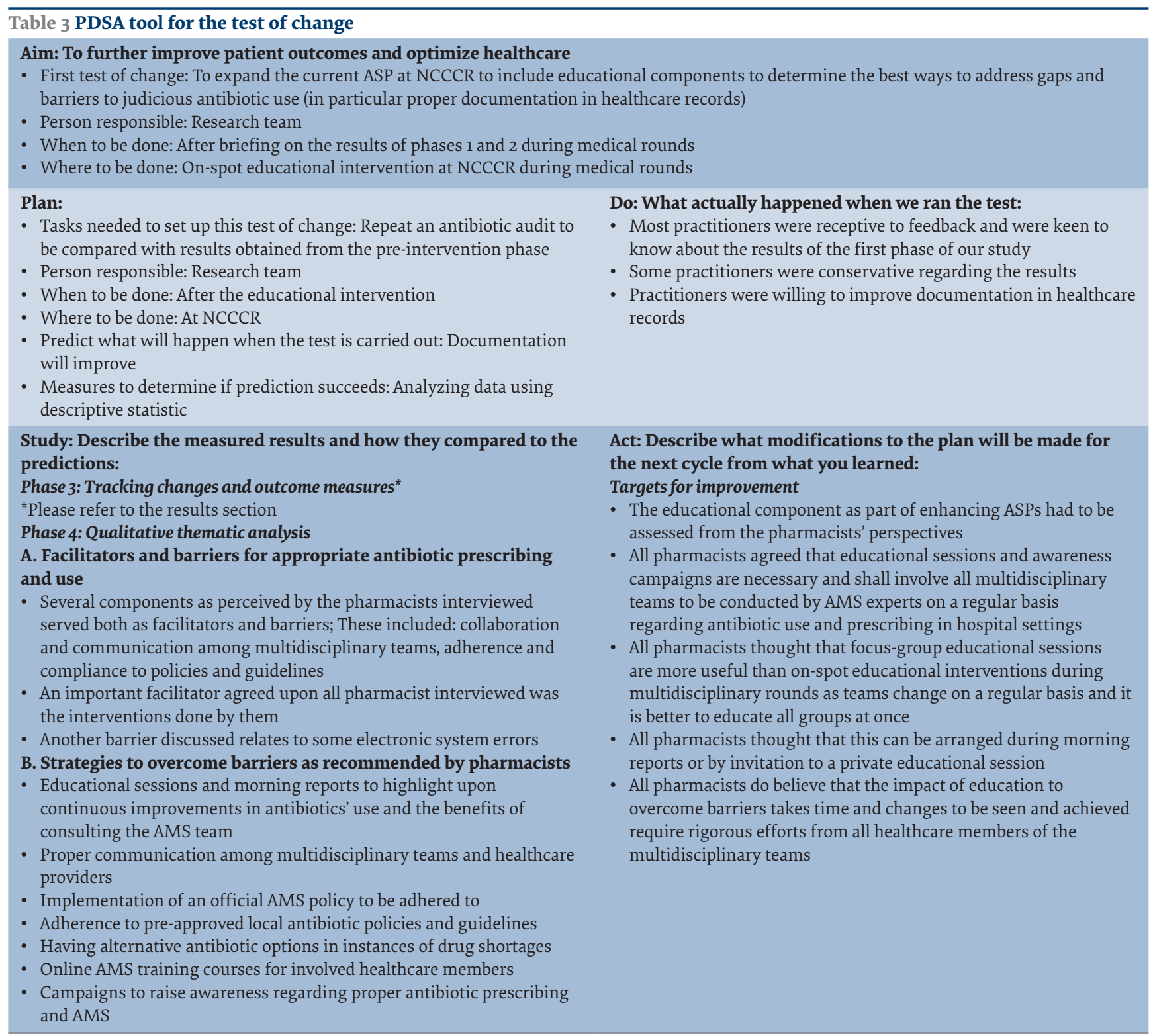

\section{Phase 2: Feedback using an educational intervention}

Several recommendations and targets for improvement in antibiotic use and prescribing behaviours emerged after analysing the results of phase 1 of our study. The main focus was on proper documentation in electronic health records, which helps improve collaboration between healthcare practitioners. Making such information accessible will further help ensure that antibiotics are used properly, modified as needed, and discontinued in a timely manner. In fact, we put emphasis on the appropriate documentation of: indication of the antibiotic based on local prescribing policies or international guidelines (whenever it is recommended to start or continue an antibiotic); rationale behind not adhering to guidelines when applicable; intended duration of treatment course (automatic stop order in CERNER ${ }^{\circledR}$ vs. actual intended duration); indication for prophylaxis; and the reason behind stopping, discontinuing, changing, or adjusting a current antibiotic based on culture and sensitivity results or patient's actual condition. In order to address the aforementioned recommendations, an on-spot educational intervention was developed.

\section{Phase 3: Tracking changes and outcome measures}

Sixty-four medical records were assessed for inclusion in the repeated audit. Twenty-four records were only reviewed as patients in those records were receiving at least one antibiotic on the day of the study audit. Documentation in electronic health records was sub-optimal. In $60 \%$ of the cases where there was proper documentation, the rationale behind adjusting a treatment regimen based on sensitivity results, or even stopping an antibiotic because of no clear indication was documented by clinical pharmacists. Table 3 summarizes the results of phase 3 . 
Table 4 Documentation in healthcare records (indication, duration of therapy, antibiotic treatment plan/change rationale) post the educational intervention

Documentation just for clinical indication

$\mathrm{N}=5(20.8 \%)$

$\mathrm{N}=4(16.7 \%)$

$\mathrm{N}=15(62.5 \%)$

- $\mathrm{N}=6(40.0 \%)$

- $\mathrm{N}=9(60.0 \%)$

- Due to intervention made by clinical pharmacist

- Documentation by physician

Total

$\mathrm{N}=24(100 \%)$

\section{Phase 4: Qualitative thematic analysis}

A total of three pharmacists who witnessed the educational intervention participated in the semi-structured interviewing process. All pharmacists were females and practice at NCCCR as members of infectious diseases, haematology and oncology multidisciplinary teams. Two major themes relating to AMS were identified throughout the interviews: facilitators and barriers. Recommendations to overcome perceived barriers were also interpreted as a sub-theme. Table 4 summarizes the results of phase 4.

\section{Discussion}

The results of our PPSs showed some improvement in AMS practices compared to a previous study (19), which signals a culture of AMS may be developing at our institution. However, a gap was exposed in terms of the documentation available for clear understanding of antibiotic prescribing practices. These results are important, as our institution recently switched to an electronic healthcare record system. As documentation practices differ from previous handwritten notes in medical charts, our results and interpretations are likely very relevant to other centers undergoing similar changes.

While documentation emerged as the area with the most room for improvement in our study, its implications are controversial. Also, we cannot directly judge that $62.5 \%$ of cases had proper documentation because of our educational intervention. This might be possibly due to the Hawthorne effect (26). The importance of this issue is still an area of debate, especially that there is no wellestablished evidence in primary literature that requires clinical practitioners to document their rationale behind adhering or not to widely adopted clinical practice guidelines (27). However, best practices should advocate for detailed documentation in the patient medical file. By doing so, decision-making becomes transparent and can be followed and understood throughout transition points in care and also transition of prescribers.

Another important finding emerged from our follow-up period that occurred immediately after the PPSs. Specifically, clinical pharmacists documented the rationale for the majority of documented antibiotic therapy decisions and interventions. Clinical pharmacists, as members of the multidisciplinary team, are essential leaders of antimicrobial stewardship programmes due to their expertise in drug therapy, and influencing the antibiotic misuse within hospital settings (28-30). Our results support their role on AMS services and specifically support advanced roles that include documentation in the patient healthcare record. As such, team communication can be facilitated and seamless care will be ensured.

The interventional portion of our study aligns with research from other centres. Previous studies carried out in the United States of America, Canada, and Europe showed the importance of antimicrobial stewardship quality improvement tools (such as the PDSA cyclesbased educational interventions) in increasing rates of appropriate antibiotic use and the compliance with antibiotic prescribing policies and guidelines (31-33). We attempted to use this model to improve documentation practices. The educational messages were received positively yet impacts on practice are still unclear. Achievement of practice change can be very difficult, especially with rotational staff and frequent addition of medical residents and fellows to multidisciplinary teams. Therefore, it is likely that repeated educational interventions might be required to promote a culture of change and embed good documentation habits within the practice culture.

The final analysis of facilitators and barriers can help us learn from this experience and provide insight for other institutions attempting to implement similar interventions. First, communication was identified as both a facilitator and a barrier. As all education is based on communication, those completing the intervention must be good communicators and have experience discussing clinical practices with multidisciplinary teams. Secondly, clinical pharmacists believed that clinical pharmacist interventions are well received and that these team members can promote proper use of antibiotics. Thirdly, the use of an electronic health system with automatic prescription durations and renewals was seen as a barrier to AMS. This point stresses the need for better documentation of therapy plans (including intended duration of therapy), in order to optimize practices at transition points in care. By considering these three key points, it is likely that uptake of AMS interventions can be increased.

Several limitations should be highlighted upon in our study. First, all patients audited in this study had a primary diagnosis of cancer, an immunocompromised condition. Thus, utilization of antibiotics administered in different populations cannot be generalized and does not reflect all antibiotic-prescribing behaviours throughout 
Qatar. Secondly, it was a single centre study but it is likely that the interpretations of our data are relevant to other centres. Lastly, results were descriptive in nature due to the challenges identified in comparing practices that occurred before and after our intervention. Specifically, we could not rule out a high risk of confounding if statistical comparisons were made. However, the descriptive snapshots provide rich data that allows for great insight into AMS implementation within our center.

\section{Conclusions}

Our findings show that antimicrobial stewardship measures have slightly improved over the last three years at our institution. However, clinicians are still not following prescribing guidelines at all times. Also, our findings expose a gap that clinicians are not consistently documenting the rationale for the use of antibiotics in the medical records and that educational interventions could be considered as an interventional strategy for future improvement. We recommend open forum discussions and weekly review meetings to address malpractice with continuous efforts to improve documentation, in order to facilitate communication among healthcare team members. Facilitators to this practice change can include improved team communication and inclusion of clinical pharmacists on multidisciplinary teams. Our results also suggest that practice changes take time and cannot be expected after one educational intervention. Therefore, educational programs should be longitudinal, repetitive, and based on specific individual and/or institutional observed behaviors. Future studies should be designed to assess such programs and the ability of ASPs to create a culture of continuous quality improvement.

Funding: This report was made possible by a UREP award [UREP18-033-3-010] from the Qatar National Research Fund (a member of The Qatar Foundation). The statements made herein are solely the responsibility of the author[s].

Competing interests: None declared.

\section{Implications en matière de pratiques de prescription suite à une intervention de gestion des antimicrobiens dans un hôpital universitaire de soins tertiaires au Qatar}

\section{Résumé}

Contexte: Le mauvais usage des antibiotiques constitue un problème de santé publique à l'échelle mondiale; il est associé à une hausse de la morbidité, à un allongement du temps d'hospitalisation, à une augmentation de la mortalité et des coûts des soins de santé, et surtout à la résistance aux antibiotiques.

Objectifs : L'objectif de la présente étude était de mesurer la conformité des prescriptions d'antibiotiques avec les directives nationales, d'évaluer la façon dont les interventions éducatives peuvent être utilisées au mieux pour avoir un impact et combler les lacunes en vue d'une utilisation optimale des antibiotiques, et d'identifier les facteurs favorables et les barrières à la mise en œuvre de programmes de gestion des antimicrobiens au Qatar.

Méthodes: Six vérifications de référence transversales de la prescription d'antibiotiques ont été conduites sur une période de deux semaines dans un hôpital universitaire de soins tertiaires. Nous avons ensuite procédé à une sousanalyse des prescriptions ainsi qu'à un suivi des comportements de prescription. Une intervention éducative reposant sur la méthode PDCA (planifier-développer-contrôler-ajuster) a été mise en œuvre afin de combler les lacunes identifiées. Une deuxième série de vérifications a été conduite afin d'évaluer l'impact du changement. Enfin, des entretiens ont été menés afin de reconnaître les facteurs favorables et les barrières perçus pour la mise en œuvre de programmes de gestion des antimicrobiens, d'identifier des stratégies pour faire tomber ces barrières, et d'évaluer l'efficacité des interventions éducatives.

Résultats : La neutropénie fébrile était l'indication la plus courante pour la prescription d'antibiotiques (20,7\%). La classe d'antibiotiques utilisée le plus fréquemment était celle des carbapénèmes (21,4\%). Soixante pour cent des prescriptions étaient conformes aux lignes directrices. Les raisons qui justifiant le non respect de ces dernières n'étaient pas documentées dans 37,2 \% des cas. Notre intervention se concentrait également sur la documentation sous-optimale des comportements en matière de prescription dans les dossiers médicaux. Une légère amélioration a été notée dans ce domaine lors de l'intervention post-vérification. Les facteurs favorables et les barrières incluaient : la collaboration et la communication entre les équipes, la conformité avec les lignes directrices, les interventions documentées par les pharmaciens cliniciens, et les erreurs de systèmes électroniques.

Conclusions : Une communication efficace, une documentation constante des comportements en matière de prescription dans les dossiers médicaux, et la formation continue des personnels encouragent une prescription rationnelle des antibiotiques et renforcent les programmes de gestion des antimicrobiens. 


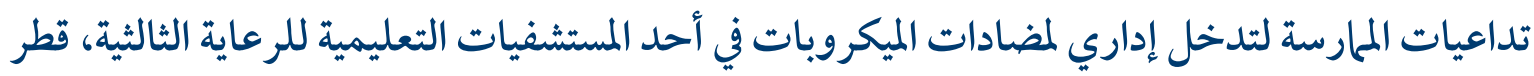

زياد نصر، علياء بابكر، مروة البشير، عائشة عثمان، شيرين العزازي، كايل ويلبي

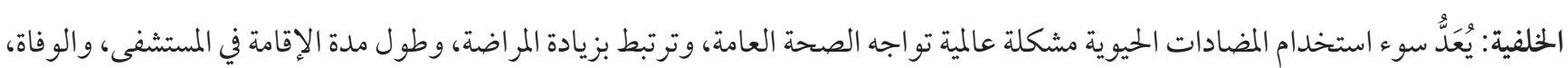

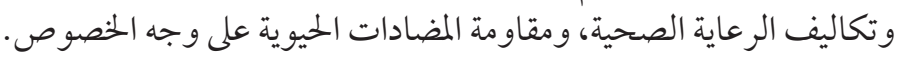

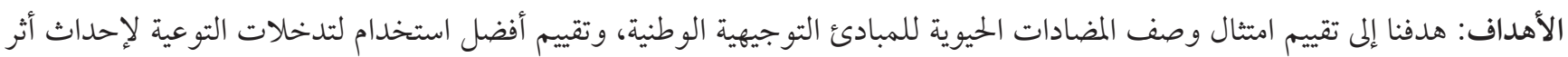

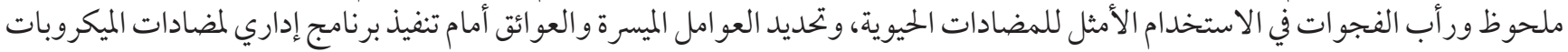
في قطر.

طرق البحث: أُجريت ست عمليات تدقيق أساسية مقطعية لوصف المضادات الحيوية على مدار أسبوعين في أحد المستشفيات التعليمية للرعاية

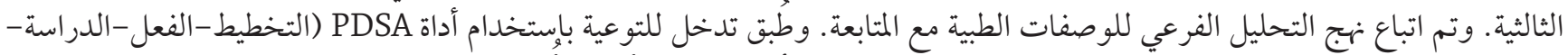

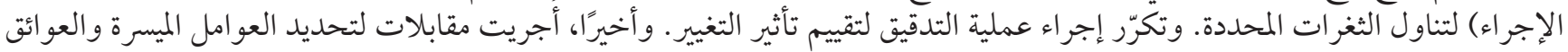

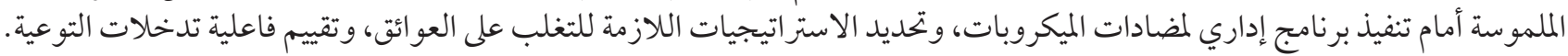

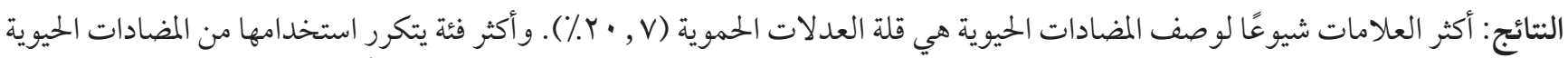

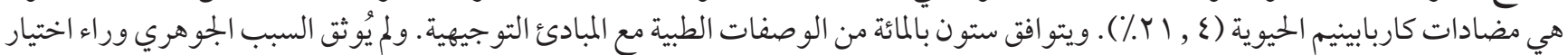

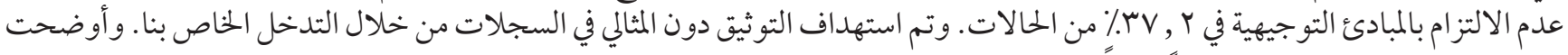

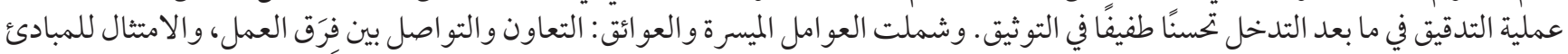

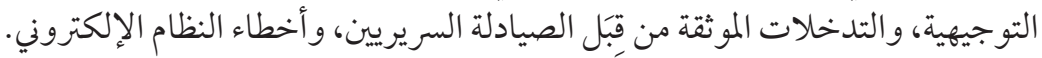

الاستنتاجات: يساعد التواصل الفعّال، والتوثيق المستمر في السجلات، والتوعية المتكررة في تعزيز وصف المضادات الحيوية على نحو معقول وويُحسّن من تنفيذ برنامج إداري لمضادات الميسات الميكروبات.

\section{References}

1. U.S. Food \& Drug Administration. Combatting antibiotic resistance; [updated 2011 November 15] (http://www.fda.gov/).

2. Tverdek FP, Rolston KV, Chemaly RF. Antimicrobial stewardship in patients with cancer. Pharmacotherapy. 2012;32(8):722-34. http://dx.doi.org/10.1002/j.1875-9114.2012.01162.x

3. Sanchez GV, Fleming-Dutra KE, Roberts RM, Hicks LA. Core elements of outpatient antibiotic stewardship. Centers for Disease Control and Prevention. 2016; 65(6):1-12 (http://www.cdc.gov/).

4. Tamma P, Cosgrove S. Antimicrobial stewardship. Infect Dis Clin N Am. 2011; 25(1):245-260. Clin Infect Dis. 2016;62(10):e51-77.

5. Baram TF, Cosgrove SE, Abbo LM, MacDougall C, Schuetz AN, Septimus EJ, et al. Implementing an antimicrobial stewardship program: Guidelines by the Infectious Diseases Society of America and the Society for Healthcare Epidemiology of America. Clin Infect Dis. 2016;62(10):e51-77.

6. Goff DA, Bauer KA, Reed EE, Stevenson KB, Taylor JJ, West JE. Is the "low-hanging fruit" worth picking for antimicrobial stewardship programs? Clin Infect Dis. 2012;55(4):587-92. http://dx.doi.org/10.1093/cid/cis494

7. Drew R. Antimicrobial stewardship programs: How to start and steer a successful program. JMCP. 2009:S18-23.

8. Bal AM, Gould IM. Antimicrobial stewardship programs: overcoming implementation barriers. Curr Opin Infect Dis. 2011;24:357-62. http://dx.doi.org/10.1097/QCO.obo13e3283483262

9. Khalili H, Farsaei S, Rezaee H, Dashti-Khavidaki S. Role of clinical pharmacists' interventions in detection and prevention of medical errors in a medical ward. Int J Clin Pharm. 2011;33(2):281-4. http://dx.doi.org/10.1007/s11096-011-9494-1

10. Aldeyab MA, Kearney MP, McElnay JC, Magee FA, Conlon G, Gill D, et al. Point prevalence survey of antibiotic prescriptions: benchmarking and patterns of use. Br J Clin Pharmacol. 2011;71(2):293-6. http://dx.doi.org/10.1111/j.1365-2125.2010.03840.x

11. Naughton C, Hennessy Y, Mannion C, Philbin M. A comparison of antibiotic point prevalence survey data from four Irish regional/general hospitals. Ir J Med Sci. 2011;180(2):457-61. http://dx.doi.org/10.1007/s11845-011-0677-5

12. Zarb P, Amadeo B, Muller A, Drapier N, Vankerckhoven V, Davey P, et al. Identification of Targets for Quality Improvement in Antimicrobial Prescribing: The Web- Based ESAC Point Prevalence Survey 2009. J Antimicrob Chemother. 2011;66(2):443-9. http:// dx.doi.org/10.1093/jac/dkq430

13. National Quality Forum (NQF). National Quality Partners Playbook: Antibiotic Stewardship in Acute Care (http://www.qualityforum.org/Home.aspx).

14. Gravatt LAH, Patterson JA, Franzese S. Educational antimicrobial stewardship strategies. Curr Treat Options Infect Dis. 2016;8(2):84-92. http://dx.doi.org/10.1007/s40506-016-0073-9 
15. Holland T, Fowler VG Jr, Shelburne SA 3rd. Invasive gram-positive bacterial infection in cancer patients. Clin Infect Dis. 2014;59 Suppl 5:S331-4. http://dx.doi.org/10.1093/cid/ciu598

16. Perez F, Adachi J, Bonomo RA. Antibiotic-resistant gram-negative bacterial infections in patients with cancer. Clin Infect Dis. 2014;59 Suppl 5:S335-9. http://dx.doi.org/10.1093/cid/ciu612

17. Rosa RG, Goldani LZ, dos Santos RP. Association between adherence to an antimicrobial stewardship program and mortality among hospitalized cancer patients with febrile neutropenia: a prospective cohort study. BMC Infect Dis. 2014;14(1):286. http:// dx.doi.org/10.1186/1471-2334-14-286

18. Hammuda A, Hayder S, Elazzazy S, Black E. Point Prevalence Survey of Antimicrobial Utilization in Oncology Patients. J Infect Dev Ctries. 2013;7(12):990-3. http://dx.doi.org/10.3855/jidc.3126

19. Ansari F, Erntell M, Goossens H, Davey P. The European Surveillance of Antimicrobial Consumption (ESAC) Point-Prevalence Survey of Antimicrobial Use in 20 European Hospitals in 2006. Clin Infect Dis. 2009;49(10):1496-504. http://dx.doi. org/10.1086/644617

20. WHO Collaborating Center for Drug Statistics Methodology. Guidelines for ATC Classification and DDD Assignment 2012. Oslo, 2011.

21. Freifeld AG, Bow EJ, Sepkowitz KA, Boeckh MJ, Ito JI, Mullen CA, et al. Clinical practice guideline for the use of antimicrobial agents in neutropenic patients with cancer: 2010 update by the Infectious Diseases Society of America. Clin Infect Dis. 2011;52:e56-93.

22. Gilbert DN. The Sanford Guide to Antimicrobial Therapy 2016. 46th ed. Sperryville (VA): Antimicrobial Therapy, Inc.; 2016.

23. Institute of Healthcare Improvement. Plan, Do, Study, Act (PDSA) Worksheet. Available from: http://www.ihi.org/

24. Speroff T, O'Connor GT. Study Designs for PDSA Quality Improvement Research. Qual Manag Health Care. 2004;13(1):17-32. http://dx.doi.org/10.1097/00019514-200401000-00002

25. Patton MQ. Qualitative Research \& Evaluation Methods: Integrating Theory and Practice. 4th ed. Thousand Oaks (California): SAGE Publications, Inc.; 2015.

26. Dik JW, Hendrix R, Lo-Ten-Foe JR, Wilting KR, Panday PN, van Gemert-Pijnen LE, et al. Automatic day-2 intervention by a multidisciplinary antimicrobial stewardship team leads to multiple positive effects. Front Microbiol. 2015;06:546. http://dx.doi. org/10.3389/fmicb.2015.00546

27. Wilbur K, El Kassem W, Abdulrahman A, Raghab A, Elgaily DE, Sahal AO, et al. Should clinical practitioners, as part of institutional or accreditation standards, be required to document their rationale when choosing not to adhere to widely accepted clinical practice guidelines? CJHP. 2013;66:253-5.

28. Heil EL, Kuti JL, Bearden DT, Gallagher JC. The essential role of pharmacists in antimicrobial stewardship. Infect Control Hosp Epidemiol. 2016;37(7):753-4. http://dx.doi.org/10.1017/ice.2016.82

29. ASHP Statement on the Pharmacist's Role in Antimicrobial Stewardship and Infection Prevention and Control. ASHP Statement on the Pharmacist's Role in Antimicrobial Stewardship and Infection Prevention and Control. Am J Health Syst Pharm. 2010;67(7):575-7. http://dx.doi.org/10.2146/sp100001

30. Messina AP, van den Bergh D, Goff DA. Antimicrobial stewardship with pharmacist intervention improves timeliness of antimicrobials across thirty-three hospitals in South Africa. Infect Dis Ther. 2015;4(S1) Suppl 1:5-14. http://dx.doi.org/10.1007/s40121-0150082-X

31. Thompson C, Zahradnik M, Brown A, Fleming DG, Law M. The use of an IV to PO clinical intervention form to improve antibiotic administration in a community based hospital. BMJ Quality Improvement Reports. 2015. Available from: http://qir.bmj.com/ content/4/1/u200786.w2247.full

32. Thakkar K, Gilchrist M, Dickinson E, Benn J, Franklin BD, Jacklin A, et al. A quality improvement programme to increase compliance with an anti-infective prescribing policy. J Antimicrob Chemother. 2011;66(8):1916-20. http://dx.doi.org/10.1093/jac/dkr207

33. Hingorani R, Mahmood M, Alweis R. Improving antibiotic adherence in treatment of acute upper respiratory infections: a quality improvement process. Journal of Community Hospital Internal Medicine Perspectives. 2015; 5:27472. DOI:10.3402/jchimp. v5.27472. 